\title{
Construcción de la conciencia crítica e hibridación: Dos constantes en la obra de Manuel Vázquez Montalbán
}

\author{
JOSÉ MARÍA IZQUIERDO \\ Universitetet i Oslo \\ -What have they done to my song, ma? \\ (...) \\ A ti sí que te han cambiado la canción, master. (Vázquez. El pianista 67-8)
}

La apertura de algunas de las fosas comunes de los muertos desaparecidos durante la Guerra civil española y la promulgación de la Ley de la Memoria histórica (31.10.2007) son dos hitos que, acompañados de una amplia campaña mercadotécnica promovida por las editoriales españolas, ha consolidado una aparentemente novedosa narrativa de la memoria de la Guerra civil y su posguerra. Estas novelas -a diferencia de las que se escribieron con el mismo tema en los años 1938-1975 y posteriormente durante los años 80-90- han sido escritas por autores que no participaron en la Guerra civil y/o que no vivieron la posguerra. Las novelas escritas durante los doce primeros años del actual siglo XXI son novelas que tratan del tema de la recuperación de la memoria de un momento trágico de la historia española basándose en la búsqueda de fuentes documentales en archivos y bibliotecas. Búsqueda que en muchas de esas novelas constituye la trama de las mismas. Lo que se suele apuntar como novedoso de esta última narrativa es tanto la hibridación entre ficción e historia, como sus rasgos 'autoficcionales' ya sean estos definidos según los presupuestos de Manuel Alberca del Pacto ambiguo: de la novela autobiográfica a la autoficción (2007) o los de Philippe Lejeune del Le pacte autobiographique $(1975,2005)$. En todas esas novelas en mayor o menor grado se pone de manifiesto una interpretación actual de sucesos ocurridos durante la contienda civil. En ellas se produce una actualización anacrónica -deseada o no- de las fuentes utilizadas apareciendo anacronismos de carácter histórico, sociolingüístico ${ }^{1}$ o bien de carácter

\footnotetext{
${ }^{1}$ Como en Cartas desde la ausencia (2008) de Emma Riverola (1965) donde contrasta el realismo documental de unas cartas censuradas por estalinistas y falangistas o la reproducción veraz de unos correos electrónicos con una no diferenciación sociolectal del idioma de los personajes.
} 
ideológico ya que se expresan en los textos ideas ajenas a las existentes en el conflicto. En líneas generales aparece una tendencia a asumir el denominado "Espíritu de la transición”² democrática frente al desorden producido por la lucha de clases e ideas que fue la Guerra civil española y su posguerra.

Las mencionadas novelas tienen un conjunto de características que pueden resumirse en la hibridación del texto novelesco con el relato supuestamente testimonial $^{3}$ o bien el configurado a través de la búsqueda de documentaciones ${ }^{4}$ que atestigüen el pasado real del protagonista, en otras palabras la fuente de su identidad individual o de los hechos narrados. De esa forma se articula en general un discurso crítico con las actitudes y acciones del periodo histórico nombrado en base a la presentación de la vida de unos personajes víctimas pasivas de unos hechos que no controlaban. Todo ello presupone no solamente la adopción de modelos literarios y de pensamiento que cuestionan el propio valor de la historia en la explicación del presente sino que además desactivan ideológicamente unos hechos de carácter fundamentalmente político. La mencionada actualización producida en el campo de la literatura, el cine ${ }^{5}$ y la televisión ${ }^{6}$ presupone -en algunos casos- una revisión histórica de gran importancia social ya que la opinión pública en España se ha formado y forma preferentemente a través de obras de carácter ficcional y no ensayístico. En realidad el fenómeno no es nuevo, lo novedoso en este caso es la aparición de un discurso de la "posmemoria" (Hirsch 1997) que se asemeja a las actitudes reconciliadoras y superadoras del pasado de novelistas de los años sesenta como, por ejemplo, José María Gironella $^{7}$ (1917-2003), aunque ahora lo hagan a partir de los presupues-

$-$

${ }^{2}$ Basado en la reconciliación nacional y en una amnesia política legislada con la promulgación de la amnistía general de 1977 y la legalización de los partidos políticos entre enero y abril del mismo año. En concreto en los artículos primero y segundo de la Ley 46/1977.

${ }^{3}$ El día de mañana (2011) de Ignacio Martínez Pisón.

${ }^{4}$ Como La fiesta del oso (2009) de Jordi Soler (1963)

${ }^{5}$ Por ejemplo: Soldados de Salamina. Versión cinematográfica (2002) de David Trueba de la novela del 2001 del mismo título de Javier Cercas.

${ }^{6}$ Amar en tiempos revueltos serie de Televisión Española estrenada en septiembre de 2005. Otro ejemplo es Cuéntame cómo pasó serie de la misma cadena de televisión estrenada en septiembre de 2001 y que lleva ya más de doscientos episodios.

${ }^{7}$ Entre otras Un millón de muertos (1961) y Ha estallado la paz (1966) 
tos asumidos consciente o inconscientemente del individualismo imperante hoy en día que no es ajeno a la actual hegemonía del liberalismo.

Una novela no es solamente un objeto estético, tal y como defendió Mijaíl Bajtín en su Teoría y estética de la novela, o un sistema de comunicación mediato en palabras del Yuri Lotman de la Estructura del texto artístico, sino que también es una forma de conocimiento y un canal informativo establecido por medio del contrato genérico novelístico. En el caso de la novela histórica y memorística ese proceso epistemológico se basa en una racionalización del pasado tomando al mismo tiempo una postura frente a la historia a través de su actualización en el presente. Un buen ejemplo en las letras hispánicas es el de la novela de Benito Pérez Galdós (1843-1920) La Fontana de oro (1870) donde se observa la intencionalidad de Pérez Galdós al utilizar los hechos relatados en torno al Trienio liberal español (1820-23) para adoptar una postura frente a los hechos de la Revolución Gloriosa (1868).

Los novelistas escriben sobre hechos históricos por medio de sus recuerdos o bien en base a documentos, pero tanto la memoria como la selección documental responden a criterios basados en el ahora del momento de la escritura del texto. A su vez el proceso de leer una novela está marcado por contratos de lectura generados por las propias características genéricas, estilos autoriales o por convenciones marcadas por guiños al lector en forma de citas reconocibles, paratextos, etc. "Este contrato de lectura genera en el lector una determinada predisposición frente al texto" (Pons 29), de alguna manera es una regulación de la producción de sentido en la lectura del mismo. En el caso de la narrativa de la memoria de la Guerra civil de los últimos años el mencionado pacto de lectura se fundamenta en una actitud desiderativa por ver recuperadas esas partes de la historia española desde una perspectiva superadora de los antagonismos de los años treinta. En otras palabras se produce una mixtificación de lo que se pretende recordar para que sea asimilable por el lector actual. Se recuerda lo deseado, no lo sucedido, se revive el enfrentamiento civil de forma ficticia, desde una actitud tolerante, acrítica e individualizada del pasado más acorde con el presente que con el tiempo de la contienda civil.

En palabras del historiador Juan Sisinio Pérez Garzón, "el proceso de construcción de cada memoria siempre es una elaboración política” (24), una forma de justificar y explicar el presente de un colectivo social determinado defendiendo su futuro. En otras palabras la memoria, las múl- 
tiples memorias, están en la base de la construcción de toda identidad y por eso mismo la memoria nunca es neutral sino que responde a determinados presupuestos ideológicos o políticos.

Los autores de la novela de la memoria del siglo XXI no dan testimonio directo de la Guerra civil porque no la vivieron ${ }^{8} \mathrm{y}$ al escribir sobre la misma o sobre su posguerra lo hacen desde el actual desencanto hacia la acción política, donde resultan inaceptables (Izquierdo. "Maquis..." 114) los discursos ideológicos de los años treinta. En general estas novelas de los últimos doce años critican indirectamente el desorden generado por el combate ideológico, relativizan las responsabilidades de los protagonistas individuales inmersos en problemáticas creadas por dirigentes y grupos hegemónicos del poder e inscriben su diégesis en la perspectiva socio-pragmática de un tiempo diferente al de la Guerra civil ${ }^{9}$.

En casi todos estos casos al autor no le basta para elaborar su discurso con lo expresado por los personajes de esas novelas y relatos sino que precisa del apoyo documental explícito y no meramente integrado en la narración. En estas novelas el aspecto físico del libro ${ }^{10}$ es fundamental, incorporando fotografías de documentos, iconos culturales etc. que faciliten el diálogo entre lo claramente ficticio y lo documental histórico. El objeto-libro se convierte así en el reflejo de construcción de la trama narrativa basada fundamentalmente en la investigación documental o bien en la narración del “yo". Esa inclusión del documento histórico en la obra de ficción o la de un aparato bibliográfico en forma de notas a pie de página, bibliografías, etc presupone una ruptura de las fronteras genéricas, y a su vez facilitan una actualización de la fuente histórica en el

\footnotetext{
$-$

${ }^{8}$ A diferencia de entre otros Arturo Barea (1897-1957) La forja de un rebelde 1940-45), Max Aub (1903-1972) El laberinto mágico (1943-67), Ramón J. Sender (1901-1982) Crónica del alba (1942-1966) y Juan Gil Albert (1904-1994) Crónica general (1995), que son los autores que han tratado mejor sobre el tema con conocimiento directo de los sucesos.

${ }^{9}$ Me refiero aquí a novelas como Soldados de Salamina (2001) de Javier Cercas (1962), La noche de cuatro caminos (2001) de Andrés Trapiello (1953), Cartas desde la ausencia (2008) de Emma Riverola (1965), La fiesta del oso (2009) de Jordi Soler (1963) o El día de mañana (2011) de Ignacio Martínez Pisón (1960).

10 Para ver el aspecto gráfico de algunas de estas novelas ir a página web: <http://www.enmitg.com/izquierdo/literatura/articulos/escribirdeoidasppt.pdf>, diapositivas 10-14.
} 
acto de la escritura. Actualización en forma de una reescritura anacrónica del periodo histórico tratado.

\section{La Caja de Pandora: Hibridación y “collage”}

\footnotetext{
-¿Cómo interrelaciona la poesía, los ensayos, el periodismo y las novelas?

-Tengo el mismo sistema de construcción, las mismas obsesiones, el mismo amateurismo lingüístico y el mismo recurso al collage en mis columnas periodísticas, poemas, libros de ensayos y novelas. Lo que cambia es la relación formal en función de la materia prima de cada desafío. (Pérez)
}

Los fenómenos de la hibridación narrativa, del uso de subgéneros; los desdoblamientos en las voces del autor, narrador y personaje/s o las novelas del "yo" no son, en realidad, novedosos en la literatura española actual, Manuel Vázquez Montalbán (a partir de ahora lo mencionaremos con las siglas MVM) tiene ejemplos de todo ello. En realidad será él el que -en un contexto determinado bajo la dictadura franquista y tras los movimientos de las nuevas culturas- abra la "Caja de Pandora" difuminando las fronteras intergenéricas a través de la utilización del "Collage/Pastiche” de tanto intertextualidades, paratextos y referencias, como de la hibridación de géneros. MVM será desde sus inicios como escritor una "rara avis" en el panorama literario español. Sus raíces nacieron de la cultura popular mestiza tanto en términos etnográficos, como estéticos. Asimismo defendió siempre el compromiso político del autor criticando el elitismo cultural subyacente en las obras de los autores coetáneos y hasta de los catalogados -como él- en la antología poética de Josep Maria Castellet (1970). En momentos en los que se cuestionaba la función social del arte defendió un modelo en el que se patentiza el mismo interés que en las novelas de Pérez Galdós y Pío Baroja por intervenir en el debate social y político del momento, aunque con un uso de la ironía que permitía y permite la interpretación abierta de sus textos. No crea objetos ejemplares sino textos que abren la posibilidad de la reflexión una vez desveladas las raíces del desorden del poder. Uno de los grandes aciertos de MVM fue la elección del subgénero policiaco como vehículo instrumental de su visión crítica de la realidad, una mediación entre él y el lector basada, no lo olvidemos, en la ficción literaria.

el origen de su vida detectivesca fue el resultado de una apuesta irresponsable, pactada un día en que sin duda habíamos bebido demasiado y yo dije que estaba hasta las narices de la literatura que se escribía, por hermética, ocultista, culterana y que de- 
bíamos hacer novelas de detectives y policías. Entonces los amigos me tomaron la palabra y aposté que en quince días les entregaba una novela policíaca. Me encerré durante dos semanas y así redacté Tatuaje. ${ }^{11}$ (Padura 50)

La utilización de la trama de la novela policíaca o criminal le sirvió para, asumiendo el descrédito de la novela realista decimonónica y de la del llamado realismo social, reinventar un realismo crítico basado en la figura de un antihéroe que la inhabilita para ser literatura ejemplar de carácter moralizador o panfletario. Las novelas de Carvalho buscan la complicidad de su lector tanto a partir de la inverosimilitud de su protagonista y de sus ayudantes ${ }^{12}$, como por la visión crítica que estructura el discurso político de esos textos. MVM se apropia del posmodernismo literario para actualizar su propuesta política comprometida de intelectual de la izquierda (irónica) y, en palabras de Manuel Vicent, de "pop marxista” (Alberola). No en vano el ciclo carvalhiano es una crónica que arranca en la derrota de la esperanzada utopía del 68, transcurre inmerso en el pragmatismo de la política realista de las socialdemocracias y termina con la desesperanza total de las dos últimas entregas del ciclo de Carvalho.

Carvalho es Carvalho y yo soy yo. No me hago responsable de la ideología de Carvalho, pero creo que ni su desencanto ni el mío procedan de lo encantados que estábamos Carvalho y yo en la transición española. Mi desencanto, el de Carvalho, el de

${ }^{11}$ Esta historia la ha contado MVM en varias ocasiones y de diferentes maneras, veamos algunas. "A principios de los setenta vivíamos en una dictadura literaria: o escribías como Juan Benet o no eras nadie. A los jóvenes se les exigía que escribieran el Ulises. El resto eran subliteraturas. Un día, en plena euforia etílica con mi amigo José Batlló, nos burlamos de la literatura de vanguardia y él me desafió a escribir una novela de guardias y ladrones. Acepté el reto y escribí Tatuaje en 15 días [...] Para mí, [...] era una novela experimental, ya que Carvalho no era un detective al uso. Vivía con una puta, quemaba libros, era excomunista y ex agente de la CIA." (Moret 292) "«¿Por qué te interesaste por el género?», pregunta Fuster. «Por dos coñas muy puntuales. Cuando yo era joven mi suegro me hacía muchas bromitas sobre mi capacidad para ganarme la vida.[...] Me iba provocando regularmente: ¿qué?, ¿cuándo escribes un Maigret?» «Una segunda provocación provino de unos amigos de la colección de poesía El Bardo, Frederic Pagés, Francesc Serrahima. Yo les hacía mucha coña sobre la mayúscula y la minúscula en la literatura, es una vieja manía mía... [...] Me desafiaron a escribir una novela policíaca y, contradictorio conmigo mismo, contesté que aquello lo podía hacer yo en quince días.[...] , y escribí Tatuaje.» (Blanco 139).

${ }^{12}$ En la narrativa policial se sigue el modelo del cuento popular en términos de Vladímir Propp en su Morfología del cuento en lo que respecta a la composición del protagonista y sus ayudantes. 
millones de seres humanos alimentados por las expectativas emancipatorias líricas de los años sesenta fue comprobar paulatinamente que ni la píldora anticonceptiva, ni la revolución ecologista, ni las reivindicaciones de una nueva sexualidad o el pacifismo que habían marcado la nueva esperanza laica se cumplían. (MVM. La literatura... 155-156)

Esa transformación contextual se expresará también en las novelas no integradas en el ciclo carvalhiano.

Buena parte de la coherencia del pensamiento montalbaniano es el mantenimiento a lo largo de su obra de dos constantes relacionadas con su función social como intelectual y escritor: desvelar lo ocultado y dar la palabra a los silenciados. Un buen ejemplo de lo primero será la cita siguiente de su Manifiesto subnormal (1970), texto en el que se condensa buena parte del marxismo de MVM y su peculiar relación con los géneros literarios y artísticos.

VISUALIZACIONES SINÓPTICAS propuestas a los organizadores de "Campaña de Protección Ocular” con el fin de agudizar la querencia perceptiva de los miopes, poco propensos a la particularización del detalle en un mundo en que hasta el parpadeo es lenguaje. (MVM. Manifiesto... 122)

Junto a la función desveladora del intelectual -de corte sartriano- MVM apuntará la necesidad de ir a la raíz de los fenómenos culturales vistos estos como sublimaciones de una realidad insoportable, tal y como en los casos que señalo seguidamente en los que utiliza la metáfora del canibalismo en forma de ocultación cultural, de gastronomía.

La cocina es un artificio de ocultación de un salvaje asesinato, a veces perpetrado en condiciones de una crueldad salvaje, humana, porque el adjetivo supremo de la crueldad es el de humano. Esos pajaritos ahogados vivos en vino para que sepan mejor, por ejemplo. (MVM. La Rosa... 244)

Yo suelo dar una respuesta inteligente, de la que me responsabilizo, pero Carvalho no ha dicho nada relevante al respecto. Yo suelo plantear la cocina como una metáfora de la cultura. Comer significa matar y engullir a un ser que ha estado vivo, sea animal o planta. Si devoramos directamente al animal muerto o a la lechuga arrancada, se diría que somos unos salvajes. Ahora bien, si marinamos a la bestia para cocinarla posteriormente con la ayuda de hierbas aromáticas de Provenza y un vaso de vino rancio, entonces hemos realizado una exquisita operación cultural, igualmente fundamentada en la brutalidad y la muerte. Cocinar es una metáfora de la cultura y su contenido hipócrita, y en la serie Carvalho forma parte del tríptico de reflexiones sobre el papel de la cultura. (MVM. Las recetas... 7) 
-La cultura no te enseña a vivir. Es sólo la máscara del miedo y la ignorancia. De la muerte. Tú ves una vaca en La Pampa...

- ¿Tiene que ser en La Pampa?

-En cualquier parte. La matas. Te la comes cruda. Todos te señalarían: es un bárbaro, un salvaje. Ahora bien. Coges a la vaca, la matas, la troceas con sabiduría, la asas, la aderezas con chimichurri. Esto es cultura. El disimulo del canibalismo. El artificio del canibalismo. (MVM. Quinteto... 108)

A su vez las palabras de Andrés Larios, un alter ego montalbaniano, hablando con el poumista excarcelado Albert Rosell en El pianista (1985), son un buen ejemplo de su interés por dar la voz a los derrotados.

Me gustaría saber escribir como Vargas Vila o Fernández Flórez o Blasco Ibáñez para contar todo esto, porque nadie lo contará nunca y esta gente se morirá cuando se muera, no sé si usted lo habrá pensado alguna vez. Saber expresarse, saber poner por escrito lo que uno piensa y siente es como poder enviar mensajes de náufrago dentro de una botella a la posteridad. Cada barrio debería tener un poeta y un cronista, al menos, para que dentro de muchos años, en unos museos especiales, las gentes pudieran revivir por medio de la memoria. (MVM 138-9)

MVM en El pianista defiende una concepción de la historia como fuente y raíz de conocimiento. La búsqueda de las raíces del final de la transición en un pasado próximo, en concreto en dos momentos cruciales de la historia española como son la posguerra durante los años cuarenta y los inicios de la Guerra civil. El artefacto literario se presenta como tal sin pretender reproducir el modelo del testimonio o de la búsqueda documental. MVM adopta una relación Ético/Estética que se inscribe en el marco de elaboración de una conciencia crítica ajena al discurso marcado por las ideas que originaron la transición democrática, ideas que actualmente, como ya dije anteriormente, son las hegemónicas. En su obra se establece una compleja combinación entre su pensamiento de corte marxista con ideas y conceptos como historia, utopía, lucha de clases, revolución, sujeto de la revolución, construcción de la conciencia social y política, etc., y una total hibridación de tanto géneros literarios, como de manifestaciones culturales ya sean estas -en términos de Umberto Eco- "apocalípticas o integradas".

\section{Compromiso político}


El compromiso político ${ }^{13}$ de MVM se materializó en todo el ámbito general de sus publicaciones ya fueran estas novelas, poemas, ensayos etc. El pensamiento montalbaniano será también un producto no sólo de la sociedad del espectáculo, de los medios de comunicación de masas, de la cultura, o de las posiciones estéticas del culturalismo y de la investigación lingüística de los artistas y novelistas de la Generación literaria del 68; será también una crítica de lo realmente existente sin pretender ser una alternativa positiva, sin tener un modelo global alternativo que ofrecer y que pudiera convertirse en una nueva pesadilla de la Razón instrumental: El Gulag ${ }^{14}$. Esa será la actitud del MVM del Manifiesto subnormal (1970) contraria a la alienación del individuo en un mundo dominado por el mercantilismo consumista, amoral y mistificador de las relaciones de dominación. No olvidemos que el tema de la alienación, junto al de la Teoría del valor de Marx fueron dos temas claves durante los años setenta. Asimismo los condeptos de alienación, reificación, cosificación o enajenación fueron redefinidas por Herbert Marcuse a lo largo de una obra que, aunque se publicó con retraso durante esos años en España ${ }^{15}$, fue muy leída. Así pues no es de extrañar que fuera también durante los años setenta cuando MVM presente con mayor radicalidad verbal los problemas reificadores que genera la sociedad de mercado.

\footnotetext{
"Las cuevas del Drugstore

son las cuevas de Ali Babá

pero no busque $\mathrm{Vd}$. a los cuarenta ladrones

los camareros proceden de la Harvard University

las dependientas han triunfado

en casi todos los concursos de belleza

hasta las gambas son más hermosas

que las gambas habituales

${ }^{13}$ En lo que respecta al compromiso político de MVM y sus ideas políticas seguiré a grosso modo los tres textos que publiqué en "Manuel Vázquez Montalbán y 'el tan esperado octavo día de la semana'" (2007), "Manuel Vázquez Montalbán (1939-2003) El escriba y la ciudad democrática" (2004) y "Escribas sentados en planetas de simios: Ideas políticas en la obra de Manuel Vázquez Montalbán” (2001). Ver bibliografía.

${ }^{14}$ Del asunto escribí en Izquierdo, José María, “’Negativismo crítico' versus 'Pensamiento único’ en la obra de Juan Goytisolo” (1998). Ver bibliografía.

${ }^{15}$ En 1968 publicó Seix\&Barral su El hombre unidimensional, en 1971 fue Alianza editorial la que hizo lo mismo con los títulos Razón y Revolución y La agresividad en la sociedad industrial avanzada.
}

- 
y los asesinos del pasillo central

recitan a Shakespeare

pero aún hay más

en las cuevas del Drugstore

están todos los tesoros que Vd. había olvidado

todo un catálogo de mercancías de felicidad

regalos que nadie ha imaginado regalarle

que sólo Vd. podía haberlos imaginado

porque se dirigen al centro de su frustración

y si presenta el bono adjunto

le haremos un 10\% de descuento. (MVM. Manifiesto... 87)

Un mercantilismo consumista presentado como realidad satisfactoria por unos medios de comunicación de masas dominados justamente por los propios mercaderes.

Destruida la conciencia reflexiva del pueblo mediante los bisturís eugenésicos de los mass-media, la paz de Augusto se instaura sobre el hemisferio occidental. Para impedir la evidenciación de que la subnormalidad afecta a todo ciudadano incapaz de capacidad de reflexión, la Sustancia Supersistemática promueve campañas de protección a los subnormales diferenciados, como si estos seres merecieran trato distinto al que merece el hombre sometido desde los catorce años a la weltanschauung de las relaciones de producción-trabajo-capital y a una programación de su ocio totalmente sometida a los mass-media. Los mecanismos de la conciencia subnormal común están lesionados por el virus de la reflexología publicitaria. La ley del estímulo y del reflejo lleva a dos nuevas leyes que hunden en la zona oscura de la subnormalidad a la mayoría de seres humanos.

1. La ley del hábito de la conciencia no reflexiva.

2. La ley de la asepsia moral como consecuencia de la saturación por estímulos meramente informativos. (MVM. Manifiesto... 26)

Una realidad legitimada, explicada, por una intelectualidad incapaz de ofrecer una alternativa.

El deber de todo intelectual subnormal, consciente del precario equilibrio de la tolerancia que le justifica, es saber abastecer a la sociedad de todas las chucherías que dan realce al escaparate de la prosperidad. Y el subnormal que esto suscribe, no ha vacilado en poblar el escaparate con las más luminosas significaciones de la historia cultural presente. (MVM. Manifiesto... 51-52) 
Lo que generará una visión escéptica de un mundo, de una sociedad que iniciará un proceso de consolidación de una propuesta ideológica que se auto-presentaba, y presenta, como la ideología de la no ideología.

La ideología de la no-ideología constituyó el sustrato alimenticio del criterio del ciudadano, y pronto el desencanto constituyó el sustrato alimenticio del crítico de la cultura y a la larga del propio creador. (MVM. Manifiesto... 21)

En esa dinámica acrítica se empezó a elaborar un discurso que años después será formulado como primer paso hacia el pensamiento único neoliberal y que pretendió ser la negación de la teoría crítica de corte marxista. El mismo MVM denominará esa tendencia dentro de lo que definió irónicamente como -en referencia directa de la conocida frase de Friedrich Josef Dürrenmatt (1921-90)- el vivir en tiempos donde hay que luchar por lo evidente. Lo que en términos montalbanianos era: "Asumir lo que es evidente, sin pedir explicaciones a la evidencia." (MVM. Manifiesto... 24), describiendo la realidad cultural y política tras la Segunda guerra mundial.

MVM protagonizará durante los años 60-70 una alternativa a ese proceso de desideologización aparente que se presentará desde una actitud tendente a la reflexión, a la construcción de la conciencia social, a la recuperación de la memoria, pero asumiendo en forma de mirada irónica la imposibilidad de la construcción de utopías globales, finalistas y totalizadoras. En una primera época lo hizo usando el lenguaje cuasisurrealista de Groucho Marx y en una segunda reafirmando su pesimismo intelectual, lo que no le impidió la elaboración de críticas globales a las sociedades actuales a partir de sus materializaciones concretas. Ese modelo de desalienación del individuo a través de la reflexión, de la reconstrucción de la conciencia social, de la crítica al modelo neoliberal, que tiene su origen en la sociedad surgida tras el uso de la bomba atómica, se debía realizar, según MVM, a través de la comunicación, de una acción comunicativa desarrolladora de la democracia real en el ámbito de las formas culturales, situándose así en una perspectiva que posteriormente desarrolló Jürgen Habermas.

En las sociedades avanzadas de Occidente se han desarrollado durante los dos últimos decenios conflictos que en muchos aspectos se desvían de los patrones que caracterizan al conflicto en torno a la distribución, institucionalizado por el Estado social. Ya no se desencadenan en los ámbitos de la reproducción material, (...) Los nuevos conflictos surgen más bien en los ámbitos de la reproducción cultural, la inte- 
gración social y la socialización; (...) la defensa y restauración de nuevas formas de vida amenazadas o de la implantación de nuevas formas de vida. En una palabra: los nuevos conflictos se desencadenan no en torno a problemas de distribución, sino en torno a cuestiones relativas a la gramática de las formas de la vida. (Habermas. 5556)

Evidentemente esa posición no podía ser también más que crítica, durante los años setenta ${ }^{16}$, hacia el modelo del capitalismo de estado dominante en los países autodenominados socialistas.

...el Hombre total sirvió para distraer la vista de los cuerpos exactos sacrificados a las averías del centralismo democrático o al único elán revolucionario internacionalista que manifestó Stalin: exportar un asesino para hendir como una fruta la leonina cabeza de Trotski. Y este Hombre deshumanizado, pieza satisfecha en el engranaje del tinglado neocapitalista o neosocialista, sirve para distraer la vista de los cuerpos vietnamitas o biafreños, hinchados por la muerte o por el hambre. (MVM. Manifiesto... 17)

La crítica al capitalismo realizada por MVM durante los años setenta fue una combinación de anticapitalismo, antifranquismo y socialismo antiautoritario tendente hacia un nuevo tipo de humanismo radical en el que se vislumbra -entre otros- el pensamiento de Agnes Heller (1929). La posición posterior de MVM no cambió sustancialmente, lo que se modificó fue el contexto. El franquismo y la transición serán ya meras referencias históricas, pero el capitalismo y su ideología neoliberal siguieron siendo el modelo y la ideología dominantes a los que MVM se opuso por motivos de supervivencia.

A la pesadilla utópica de Orwell de una humanidad totalizadora en 1984 podemos llegar por la fuerza del miedo a no sobrevivir, por la insolidaridad del sálvese quien pueda del totalitarismo del mercado único al servicio de una verdad única, de un discurso único fruto de un pensamiento único... (MVM. La literatura... 106)

Aparentemente su pesimismo parecerá ser una visión desencantada de la realidad, pero en realidad expresa su actividad como intelectual crítico de la misma. Un buen ejemplo es el tema de la "escalera del gallinero"

${ }^{16}$ MVM por aquellos años era un conocido opositor del franquismo y miembro del PSUC (Partit Socialista Unificat de Catalunya), el partido comunista de Cataluña. MVM anteriormente había pertenecido al Frente de Liberación Popular (FLP). 
incluido por lo menos en tres ocasiones en sus textos ${ }^{17}$ comentando la brevedad de la vida individual y política, y sus aspectos negativos.

\footnotetext{
No le quiero enseñar mis heridas de guerra, amigo, pero tiene ante usted a un antiguo combatiente antifranquista y aunque parezca increíble eso ahora no se lleva, eso ahora provoca rubor, vergüenza y mala conciencia. La vida de esta democracia es como la escalera de un gallinero: corta pero llena de mierda. (MVM. Asesinato... 25-26)

-¿Quién dijo aquello de que la vida es como la escalera de un gallinero, corta pero llena de mierda?

-Confucio. (MVM. Cuarteto 48)
}

\section{-Ahora será un secreto entre usted y yo. Usted y yo sabemos que la vida es como una} escalera del gallinero corta pero llena de mierda. (MVM. El delantero... 189)

Esa actitud existencial pesimista no supuso el abandono de un discurso político muy crítico con las expresiones artísticas que se pusieran al servicio del orden establecido, en la lógica del escriba sentado creador de simios desmemoriados. No en vano durante los años noventa publica $Y$ el viajero que huye (1990), otro texto producto del collage, de la intertextualidad, en el que se vuelve a hacer una crítica al preciosismo literario, a la literatura ensimismada y sublime contempladora de "estrellas, para no ver las ratas" (MVM. Pero el viajero... 41). En otras palabras una crítica a los discursos ideológicos ocultadores, manipuladores, de la razón de ser de las situaciones actuales. Si en 1990 hizo en clave poética una crítica hacia el arte no comprometido, en 1997 leyó, en su conferencia de aceptación del título de doctor honoris causa de la Universidad Autónoma de Barcelona, una defesa del pensamiento utópico, de su octavo día de la semana, en forma de undécima Tesis de Feuerbach.

\footnotetext{
17 "Juan Madrid la recoge también en Regalo de la casa (1986) [Tercera entrega de Toni Romano] y dice que la vio escrita en unos urinarios ¿Quién la usó primero? -Es una frase del refranero popular. La pusimos por primera vez en la revista Por Favor. La pusimos como lema en primera página. Debió ser el año 74. Recuerdo que Emilio Romero nos dedicó un editorial en Pueblo, diciendo: vaya con estos nuevos intelectuales que llegan ahora, qué definición de la vida, corta y llena de mierda, esto es llenar de mierda la inteligencia..." (Blanco 40). La última vez que aparece el mencionado refrán en alguna obra literaria es en la versión cinematográfica de la novela de Ángel Mañas, Historias del Kronen, realizada en 1995 por Montxo Armendáriz. Santos Sanz Villanueva en su La novela española durante el franquismo. Itinerarios de la anormalidad (Madrid, Gredos, 2010, 433) comenta esa frase atribuyéndosela a Confucio (sic!).
} 
Un dia o un altre, sens dubte, podríem començar a teoritzar sobre el que no ens deixen fer i reprendre la tesi de Feuerbach que recomanava deixar de pensar el món per intentar canviar-lo mitjançant la força de la unitat de professionals pràctics i teòrics, units perquè la 'comunicació global' no impliqui una desertitzadora i manipuladora 'incomunicació global'. (MVM. "Sobre la incomunicació...” 22)

\section{Conclusión}

MVM fue el más activo impulsor del mestizaje de los discursos artísticos a través del collage y de la destrucción de las fronteras canónicas genéricas. Desde el principio fue consciente de la necesidad de la hibridación de los géneros artísticos en sociedades del espectáculo en las que se cuestionaban modelos estéticos pre-establecidos y discursos totalizadores de largo alcance. Fue también -en una época en la que nadie lo pensaba- defensor de una literatura comunicativa, popular, no ensimismada y orientada al lector, como canal de un discurso ético y político no meramente interpretativo sino orientado a la transformación, al cambio social y cultural, de las sociedades modernas. Será también el autor que más insistió en el tema de la memoria histórica española, de su recuperación no en forma de mera actualización de hechos históricos pasados, sino como una explicación de una realidad desfigurada por el ocultamiento de la visión del mundo del derrotado. Una forma de viaje a unas raíces de un presente mal explicado, falseado y actualizado por la ideología dominante. Su posición será la del intelectual crítico desvelador de lo que se quiere ocultar o desvirtuar a través de los medios de comunicación de masas, crítico e irónico, incapaz de presentar alternativas concretas en positivo al desorden generado por el capitalismo, pero defendiendo la necesidad de tomar conciencia del porqué del "estado de cosas" actual para poder salir democráticamente del mismo. El proceso creativo montalbaniano irá desarrollándose hacia una posición, caracterizada por algunos como desencantada, pero que en ningún momento abandonó su actitud de desvelamiento crítico de las raíces de una ideología que desde su aparente invisibilidad se ha constituido en visión única de lo realmente existente. En realidad lo que se denomina como desencanto no es más que el malestar producido por los síntomas de la crisis global generada por la implantación del modelo social liberal.

Hoy en día nos encontramos ante unas literaturas que cuestionan el pasado como fuente explicativa del presente, que difuminan las lindes entre discurso histórico y literario y que, actualizando el pasado en discursos en gran medida anacrónicos, presuponen de una u otra forma una 
apropiación individual del mismo muchas veces en forma de novelas del “yo" y autoficciones ${ }^{18}$. Mientras en la poética montalbaniana la renovación estética, la elaboración de artefactos mestizos, tenía un ethos basado en la elaboración de discursos críticos cognoscitivos de la realidad, en una gran parte de las poéticas actuales denominadas de la memoria de la Guerra civil española la intencionalidad está cuanto menos poco clara generándose una especie de posmemoria ficcional (Marianne Hirsch 1997) que reescribe un pasado aún lamentablemente poco conocido a pesar de una ya ingente bibliografía.

\section{Bibliografía}

Alberca Serrano, Manuel. El pacto ambiguo: de la novela autobiográfica a la autoficción. Madrid: Biblioteca Nueva. 2007.

Alberola, Miquel. "Vázquez Montalbán se inspira en los Borgia para su última novela." El País (edición de Valencia). 19 mayo 1998.

Blanco Chivite, Manuel. Manuel Vázquez Montalbán \& José Carvalho. Madrid: Grupo Libro 88. 1992.

Castellet, Josep Maria. Nueve novísimos poetas españoles. Barcelona: Barral. 1970.

Lejeune, Philippe. Le pacte autobiographique. Paris: Seuil. 1975.

Habermas, Jürgen. Teoría de la acción comunicativa. Madrid: Taurus. 1987.

Hirsch, Marianne. Family Frames; Photography, Narrative and postmemory, Cambridge (Mass.) \& London, Harvard University Press. 1997.

Izquierdo, José María, “'Negativismo crítico’ versus 'Pensamiento único' en la obra de Juan Goytisolo”. Jornadas sobre Juan Goytisolo en Lund. Eds. Enkvist, Inger y Ángel Sahuquillo. Almería: Instituto de estudios almerienses, 1998: 109-125.

. "Escribas sentados en planetas de simios: Ideas políticas en la obra de Manuel Vázquez Montalbán”. Pensadores y escritores hispánicos. Eds. Enkvist, Inger y Eduardo Naranjo. Lund: Heterogénesis, 2001. 103-124.

_. "Maquis: Guerrilla antifranquista. Un tema en la literatura de la memoria española.” Actas del XV Congreso de Romanistas Escandina-

-

${ }^{18}$ Como, por ejemplo, la novela de Ignacio Martínez de Pisón (1960) Enterrar a los muertos (2005) en la que se trata del asesinato de José Robles. 
vos. Oslo 12-17 de agosto de 2002. Ed. Halvard Dørum. Oslo: Romansk forum 16:2, (2002): 105-116.

_. "Manuel Vázquez Montalbán (1939-2003) El escriba y la ciudad democrática”. Moderna språk, XCVIII, 1, (2004). 94-107

_. "Manuel Vázquez Montalbán y 'el tan esperado octavo día de la semana'." Actas del I Congreso de Hispanistas Nórdicos. Eds. Benson, Ken, José Luis Girón Alconchel y Timo Riiho. Madrid 3-5 noviembre 2004. Volumen 7 de Acta Ibero-Americana Fennica. Helsinky: Fundación Iberoamericana de Finlandia. 2007, 188-198.

Moret, Xavier. "Carvalho es el termómetro de las utopías de los sesenta y del desencanto de los noventa”. El País Digital (Madrid), 292, (19.2.1997).

Padura Fuentes, Leonardo. "Reivindicación de la memoria. Entrevista con Manuel Vázquez Montalbán.” Quimera 106-7 (1991): 50.

Pérez, María Silvia. "El escritor Vázquez Montalbán, polaco verdadero habla para La Jornada. Entrevista.” La Jornada (9.6.1996). Internet. 10 noviembre 2011.

Pérez Garzón, Juan Sisinio y Eduardo Manzano Moreno. Memoria histórica. Madrid: CSIV. 2010.

Pons, María Cristina. Memorias del olvido. La novela histórica de fines del siglo XX. Madrid: Siglo XXI. 1996.

Vázquez Montalbán, Manuel. Manifiesto subnormal. Barcelona: Kairós. 1970.

. La Rosa de Alejandría. Barcelona: Planeta. 1984.

_. El pianista. Barcelona: Seix \& Barral. 1985.

- Asesinato en Prado del Rey y otras historias sórdidas. Barcelona: Planeta. 1987.

_. Cuarteto. Madrid: Mondadori. 1988.

_. El delantero centro fue asesinado al atardecer. Barcelona: Planeta. 1988.

_. Pero el viajero que huye. Madrid: Visor. 1990.

_. Las recetas de Carvalho. Barcelona: Planeta. 1990.

_. Quinteto de Buenos Aires. Barcelona: Planeta. 1997.

_ . "Sobre la incomunicació de la societat comunicacional global.” Rectorat de la Universitat Autònoma de Barcelona-Bellaterra. 17 diciembre 1997. Discurso, doctor honoris causa.

_. La literatura en la construcción de la ciudad democrática. Barcelona: Grijalbo-Crítica. 1998. 